\title{
Odontologia Legal no ensino superior do Estado do Rio Grande do Sul
}

\author{
Alyssa Niara Brites*, Sílvia Ataide Pithan**, Marília Forgearini Nunes***, Ian Fabrício Brites****
}

\section{RESUMO}

O ensino de Odontologia Legal nos cursos de graduação em Odontologia assume importância ímpar, visto a necessidade crescente de capacitar o estudante para um ascendente campo de trabalho e oferecer formação humanista, guiada por preceitos éticos e legais. Desse modo, realizou-se um estudo exploratório sobre a oferta da Odontologia Legal e conteúdos relacionados nos cursos de graduação em Odontologia no Estado do Rio Grande do Sul, por meio da análise do Projeto Pedagógico do Curso (PPC). Quatorze (93\%) cursos participaram dessa pesquisa. Sob uma perspectiva objetiva, 36\% deles ofertam a disciplina de Odontologia Legal, enquanto 64\% não a disponibilizam. Sob uma perspectiva mais abrangente, 93\% dos cursos abordam alguma vertente da Odontologia Legal, enquanto 7\% não tratam do assunto. Sendo assim, faz-se necessária a padronização do ensino da Odontologia Legal na graduação em Odontologia.

Descritores: Odontologia Legal. Ética Odontológica. Educação em Odontologia. 


\section{INTRODUÇÃOO}

Atualmente, a complexidade dos problemas de saúde aliada às diferenças sociais e às novas opções tecnológicas, exigem tomadas de decisões seguras e com sólido embasamento ético por parte do profissional da área da saúde ${ }^{1}$. Os avanços científicos trazem a promessa da resolução de algumas doenças de maneira mais rápida e definitiva, porém é preciso tomar cuidado com conclusões precipitadas e processos que desrespeitam a bioética, colocando em risco a saúde do paciente ${ }^{2}$. Dessa forma, as instituições de ensino superior (IES) têm papel fundamental durante a formação dos cirurgiões-dentistas (CD) na condição de fornecedoras das ferramentas e conhecimentos necessários para a atuação responsável do futuro profissional.

Há a expectativa de que o profissional formado, além de ter seus valores de cidadania e os conceitos éticos inerentes à sua personalidade, atue sempre de maneira correta e com pleno respeito aos direitos humanos, independentemente de qualquer situação adversa ${ }^{1,3}$. Compreender que nem todas as circunstâncias que são legais são morais, bem como que nem tudo considerado moral está definido por lei não é uma tarefa simples ${ }^{4}$, mas deve ser estudada e debatida ao longo da formação dos futuros CD.

No entanto, nos últimos anos, tem-se constatado deficiências preocupantes nas estruturas curriculares dos cursos de graduação em Odontologia, no que diz respeito à adequação a realidade social brasileira ${ }^{5}$. Há um distanciamento entre o recurso humano formado e a população em geral, além de uma limitada visão humanista e carência de debates éticos. As críticas perpassam, também, pela valorização excessiva da técnica, dependência da tecnologia e prática eminentemente curativista ${ }^{3,6}$.

Nesse contexto, a presença da área de Odontologia Legal nos cursos de graduação em Odontologia tem importância imprescindível na formação do profissional, pois apresenta ao acadêmico efetiva aprendizagem sobre a responsabilidade ética do CD na relação profissional- paciente, bem como a interface entre Odontologia e Direito, que pode ser identificada como um novo e crescente mercado de trabalho. O acesso a uma formação que ofereça essas reflexões possibilita a formação de um profissional com conhecimento mais amplo do seu campo de atuação e capaz de trabalhar de maneira mais harmoniosa com as normas legais do país ${ }^{7,8}$.

A ausência dessa área do conhecimento pode prejudicar o futuro $\mathrm{CD}$ no que tange ao resguardo de sua atuação profissional e em eventuais processos judiciais decorrentes disso. Além disso, observa-se que esses fundamentos legais acerca da prática clínica e da perícia odontolegal têm sido exigidos, com certa frequência, em seleções públicas ${ }^{7}$.

$A$ atuação do $C D$ no âmbito da perícia

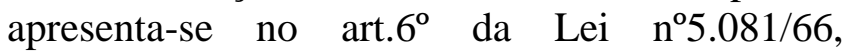
regulamentadora do exercício da profissão, onde consta entre outras competências do profissional da Odontologia, a realização de perícia odontolegal nas esferas civil, criminal, trabalhista e administrativa e o exercício da função de peritoodontólogo em casos de necropsia envolvendo a região de cabeça e pescoço ${ }^{9}$. Ou seja, ao concluir o curso de graduação em Odontologia, o CD está, teoricamente, apto a realizar suas atribuições dentro do campo da Odontologia Legal.

Destaca-se, portanto, a grandeza do elo Odontologia-Direito e a importância da colaboração do $\mathrm{CD}$ para a justiça, conforme definido na Resolução n63 do Conselho Federal de Odontologia em 08 de abril de $2005^{10}$, que estabelece os objetivos da Odontologia Legal como

“... pesquisa de fenômenos psiquícos, físicos, químicos e biológicos que podem atingir ou ter atingido o homem, vivo, morto ou ossada, e mesmo fragmentos ou vestígios, resultando lesões parciais ou totais reversíveis ou irreversíveis."

Além disso, apresenta as áreas de atuação do especialista em Odontologia Legal, como por exemplo: identificação humana, perícias nas esferas civil, criminal, trabalhista e administrativa, 
infortunística, tanatologia forense, traumatologia odontolegal, balística forense, perícia logística no vivo, no morto ou em vestígios correlatos, exames por imagem com fins periciais ou odontolegais, deontologia odontológica e orientação odontolegal para o exercício profissional ${ }^{10}$.

Diante do exposto, os objetivos desse estudo foram identificar, no Estado do Rio Grande do Sul, os cursos de graduação em Odontologia que possuem a Odontologia Legal no seu currículo, bem como analisar a abordagem da Odontologia Legal nos cursos de graduação em Odontologia no Estado do Rio Grande do Sul.

\section{METODOLOGIA}

A presente pesquisa se caracteriza como um trabalho descritivo de caráter exploratório.

Primeiramente, foi executada uma busca no endereço eletrônico do Ministério da Educação (MEC), a fim de listar todas as IES credenciadas que oferecem o curso de graduação em Odontologia no Estado do Rio Grande do Sul. Em seguida, essa lista foi confrontada com a relação de cursos de graduação em Odontologia disponível no endereço eletrônico do Conselho Regional de Odontologia do Rio Grande do Sul (CRORS). Dessa maneira, certificou-se a existência e atividade das instituições relacionadas.

Tendo como referência essa listagem, acessaram-se os sítios web de todas as instituições em busca do PPC, com ênfase na disciplina e/ou conteúdos de Odontologia Legal. No caso desses itens não estarem disponíveis na página eletrônica, realizaram-se duas tentativas de contato via email, com ofício informativo em anexo assinado pelos autores da pesquisa, endereçado à IES em questão. Não havendo resposta por parte do destinatário, efetuou-se ainda uma tentativa de contato via telefone e, persistindo a negativa do resultado, foram realizadas mais duas tentativas via e-mail, com o objetivo de atingir toda população estudada.

A etapa de obtenção dos dados foi executada durante os meses de abril, maio e junho de 2015.

\section{RESULTADOS}

Atualmente, quinze IES oferecem o curso de graduação em Odontologia no Estado do Rio Grande do Sul, sendo que quatorze participaram da pesquisa em questão, disponibilizando as informações de acordo com as suas normas. Destas, oito $(57 \%)$ colaboraram apenas com o conteúdo que já estava presente no sítio web institucional e seis $(43 \%)$ enviaram informações por e-mail, seja com o intuito de complementar o conteúdo já presente no sítio web institucional ou por não o disponibilizar na página eletrônica. Dentre as quatorze IES participantes, quatro (29\%) forneceram apenas a estrutura curricular, três (21\%) forneceram também as ementas de algumas disciplinas e sete (50\%) forneceram o PPC completo.

Tendo como base essa amostra, foi possível constatar que apenas cinco delas (36\%) ofertam uma disciplina de Odontologia Legal (tabela 1). Dessas, quatro (80\%) ministram a matéria no final do curso de graduação e uma (20\%) no início, sendo que a disciplina é de apenas um semestre em todas (tabela 2).

Deve-se ressaltar que as instituições 2, 5, 10 e 14, além de apresentarem a disciplina de Odontologia Legal nas suas estruturas curriculares, também ofertam outras matérias relacionadas à área. Entre elas estão cadeiras que abordam assuntos relacionados à Ética, Bioética e Orientação Profissional.

As outras nove (64\%) IES não disponibilizam a disciplina em questão. Porém, destes nove cursos de graduação em Odontologia que não ofertam a cadeira de Odontologia Legal, oito (89\%) cursos apresentam disciplinas relacionadas à Odontologia Legal ou conteúdos pertencentes à área sendo ministrados em outras disciplinas (tabela 3).

Sob uma perspectiva mais objetiva, pode-se constatar que $36 \%$ dos cursos de graduação em Odontologia pesquisados ofertam uma disciplina de Odontologia Legal nas suas estruturas curriculares, enquanto $64 \%$ não o fazem durante o período de graduação. 
Porém, sob um ponto de vista mais área de Odontologia Legal na sua estrutura abrangente, é cabível dizer que $93 \%$ dos cursos curricular, enquanto que um (7\%) não trata do abordam alguma vertente, mesmo que mínima, da assunto na graduação.

Tabela 1. Instituições de ensino superior que oferecem o curso de graduação em Odontologia no Estado do Rio Grande do Sul.

\begin{tabular}{ccc}
\hline Instituição & Pública ou Privada & Disciplina de Odontologia Legal \\
\hline 1 & Pública & Não \\
2 & Privada & Sim \\
3 & Privada & Não \\
4 & Privada & Não \\
5 & Privada & Sim \\
6 & Privada & Sim \\
7 & Privada & Não \\
8 & Privada & Não \\
9 & Privada & Não \\
10 & Pública & Sim \\
11 & Privada & Não \\
12 & Privada & Não \\
13 & Privada & Não \\
14 & Privada & Sim \\
\hline
\end{tabular}

Tabela 2. Cursos de graduação em Odontologia no Estado do Rio Grande do Sul que oferecem a disciplina de Odontologia Legal

\begin{tabular}{cccc}
\hline Instituição & $\begin{array}{c}\text { Número de } \\
\text { semestres }\end{array}$ & $\begin{array}{c}\text { Semestre em que a disciplina é ministrada } \\
\text { (total de semestres do curso) }\end{array}$ & $\begin{array}{c}\text { Carga } \\
\text { horária } \\
34 \mathrm{~h}\end{array}$ \\
\hline 2 & 1 & $7^{\circ}(8)$ & $40 \mathrm{~h}$ \\
6 & 1 & $3^{\circ}(8)$ & $35 \mathrm{~h}$ \\
\hline 10 & 1 & $7^{\circ}(8)$ & $45 \mathrm{~h}$ \\
14 & 1 & $10^{\circ}(10)$ & $30 \mathrm{~h}$ \\
\hline
\end{tabular}


Tabela 3. Cursos de graduação em Odontologia no Estado do Rio Grande do Sul que não oferecem a disciplina de Odontologia Legal mas que oferecem conteúdos relacionados.

\begin{tabular}{|c|c|c|c|}
\hline Instituição & $\begin{array}{l}\text { Existência de disciplina(s) } \\
\text { relacionada(s) }\end{array}$ & $\begin{array}{l}\text { Disciplina(s) } \\
\text { relacionada(s) }\end{array}$ & $\begin{array}{c}\text { Carga(s) } \\
\text { horária(s) }\end{array}$ \\
\hline 1 & Não & --- & --- \\
\hline 3 & Sim & $\begin{array}{c}\text { Orientação Profissional } \\
\text { em Odontologia }\end{array}$ & $36 \mathrm{~h}$ \\
\hline \multirow[t]{2}{*}{4} & Sim & $\begin{array}{c}\text { Orientação Profissional } \\
\text { I; Orientação }\end{array}$ & $36 \mathrm{~h}$ \\
\hline & & Profissional II & $36 \mathrm{~h}$ \\
\hline \multirow[t]{2}{*}{7} & Sim & Deontologia; & $30 \mathrm{~h}$ \\
\hline & & Ética Profissional & $30 \mathrm{~h}$ \\
\hline \multirow[t]{4}{*}{8} & Sim & Ética Geral; & $*$ \\
\hline & & Direito aplicado à & $*$ \\
\hline & & Odontologia; & \\
\hline & & Orientação Profissional & $*$ \\
\hline 9 & Sim & $\begin{array}{c}\text { Orientação Profissional } \\
\text { em Odontologia }\end{array}$ & $30 \mathrm{~h}$ \\
\hline 11 & Sim & $\begin{array}{c}\text { Ética e Legislação em } \\
\text { Odontologia }\end{array}$ & $34 \mathrm{~h}$ \\
\hline 12 & Sim & $\begin{array}{c}\text { Ética e Legislação em } \\
\text { Odontologia }\end{array}$ & $34 \mathrm{~h}$ \\
\hline 13 & Sim & $\begin{array}{c}\text { Ética e Legislação em } \\
\text { Odontologia }\end{array}$ & $34 \mathrm{~h}$ \\
\hline
\end{tabular}

*Informação não disponível no material fornecido pela Institução

\section{DISCUSSÃO}

O ensino de conteúdos de Odontologia Legal nos cursos de graduação em Odontologia tem sido tema recorrente nos eventos da área e deve, aos olhos dos especialistas, ser debatido e exposto constantemente até que os objetivos finais sejam alcançados. Objetivos esses que incluem, entre outras características, a formação de um cirurgiãodentista com entendimento mais completo sobre as suas possibilidades de atuação e que esteja preparado legalmente para sua rotina de trabalho. Além disso, segundo Oliveira et.al ${ }^{1}$,

"É de extrema importância que o cirurgiãodentista assuma um caráter ético no seu diadia, que interprete e compreenda o código de ética, propondo-se a respeitá-lo e executá-lo sempre, sem influência do temor imposto pelas punições decorrentes da sua infração."

Sendo assim, cabe às IES proporcionar meios adequados e suficientes para que os acadêmicos compreendam de maneira dinâmica uma atividade tão técnica como a do cirurgiãodentista $^{7}$.

Pode-se dizer que o âmbito das mudanças curriculares está em transição atualmente, pois nas últimas décadas tem-se preconizado o ser humano como um todo e que necessita de qualidade de vida, visão essa diferente da tendência pedagógica tradicional. Nessa perspectiva, começou-se a perceber as limitações da excessiva prática privada da Odontologia, que até então predominava integralmente. Problemas como o profissional que 
superestima os lucros usando o paciente como objeto desse processo capitalista, competição desenfreada e estratégias antiéticas deixaram de ser posturas aceitáveis ${ }^{11}$.

Nas Diretrizes Curriculares Nacionais do Curso de Graduação em Odontologia do ano de $2002^{12}$, os conteúdos essenciais estão divididos em três grupos de temas: Ciências Biológicas e da Saúde, Ciências Humanas e Sociais e Ciências Odontológicas. O segundo grupo, Ciências Humanas e Sociais, contempla que

"...os diversos conteúdos referentes às diversas dimensões da relação indivíduo/sociedade, contribuindo para a compreensão dos determinantes sociais, culturais, comportamentais, psicológicos, ecológicos, éticos e legais, nos níveis individuais e coletivos, do processo saúdedoença..."

É onde encontram-se os conteúdos de Odontologia Legal, enfoque deste trabalho. Além disso, na Resolução do Conselho de Educação Superior do Conselho Nacional de Educação $\mathrm{CES} / \mathrm{CNE} \mathrm{n}^{\circ}$ 3, local onde as diretrizes de 2002 são abordadas, destaca-se que o egresso deve ter uma formação generalista, humanística, crítica e reflexiva baseada na técnica e na ciência, além de estar apto a exercer seu papel baseado em valores éticos, legais e na compreensão da realidade social, cultural e econômica do meio em questão, visando o benefício da sociedade ${ }^{12}$.

Lemos e Fonseca (2009) ${ }^{13}$ ressaltam um ponto importante dessa questão, a de que é imprescindível que essas diretrizes e suas condicionantes sejam estudadas em suas reais condições, a fim de evitar que se tornem apenas palavras sem sentido e percam seus objetivos. Os autores também comparam a análise curricular à um novelo de lã embaraçado que, para ser desembaraçado, necessita de muito cuidado, pois está entremeado por aspectos históricos, políticos, econômicos, sociais e culturais. Devido à essa complexidade, representa um grande desafio para as IES.

Indo de encontro às recomendações estabe- lecidas na Resolução CES/CNE 03/2002, percebese que os profissionais da odontologia buscam especializar-se em alguma área, contrariando a intenção generalista nela abordada.

Gomes e Ramos $(2015)^{14}$ a partir de seu estudo para analisar a relação entre ética, especialização e mercado de trabalho na odontologia, verificaram que a especialização do profissional é uma tendência. Esse movimento estaria associado à necessidade de diferenciação no mercado de trabalho saturado pelo grande número de profissionais. Segundo os autores, surge uma fragmentação desumanizada nos cuidados à saúde bucal como subproduto da competitividade-produtividade do mercado de trabalho. A saúde bucal coletiva, nos moldes do serviço público ainda não seria vista como uma alternativa para o sucesso profissional. Esse cenário profissional atual favorece os conflitos éticos entre autonomia do sujeito baseados em conceitos de saúde, padrões de saúde/beleza, mercadologicamente construídos, necessidades de ascenção/sobrevivência do profissional no mercado de trabalho odontológico e um saberfazer especializado não subsumido ao 'dever ser' ético. Apesar de o trabalho dos autores supracitados estar relacionado ao ensino da ética e bioética nos cursos de formação latu sensu, suas considerações e observações são pertinentes e a reflexão pode ser ampliada para os cursos de graduação em Odontologia.

Todavia, os resultados apresentados por esse trabalho demonstram certa falta de padronização no ensino da Odontologia no Estado do Rio Grande do Sul, uma vez que cinco, dos quatorze cursos analisados, possuem uma disciplina de Odontologia Legal na estrutura curricular e oito ministram disciplinas ou conteúdos relativos à área, cada um de acordo com as suas particularidades. Essa característica potencializa a possibilidade de lacunas no que diz respeito ao entendimento do cirurgião-dentista sobre estar cuidando de vidas humanas, o desenvolvimento das atitudes necessárias por parte do profissional para o relacionamento humano ético, o exercício 
legal da profissão, bem como acerca do conhecimento de um campo de trabalho em forte crescimento.

Sob uma perspectiva realista e imparcial, o fato de alguns conteúdos pertencentes à área da Odontologia Legal serem ministrados como disciplina deve ser respeitado, pois os acadêmicos têm contato com os importantes conteúdos da área, mesmo com a ausência de uma disciplina específica denominada como Odontologia Legal incluída na estrutura curricular. Porém, deve-se dar ênfase e importância a estes conteúdos uma vez que a sua inclusão apenas para cumprir recomendações das DCN não garante que o objetivo será alcançado. Deve ser feita a inserção de um conteúdo adequado e relevante, bem como de problematizações pertinentes á atividade, para que haja o aprimoramento do ensino da área em todo âmbito nacional, proporcionando uma melhor formação dos recursos humanos ${ }^{15}$. $O$ futuro profissional da saúde necessita, durante a sua formação, vincular o conhecimento técnico aos conhecimentos afetivos, sociais, culturais e éticos, construindo assim uma compreensão verdadeira dos valores humanos ${ }^{16}$.

Nessa linha de raciocínio, um estudo de 2003 avaliou as estruturas curriculares dos cursos de Odontologia brasileiros e mostrou que, de uma média de 4.730 horas de carga horária total nos cursos de Odontologia do Brasil, apenas 215 horas são direcionadas para conhecimentos de Ética e Cidadania. Além disso, esse estudo tem como uma de suas conclusões o fato de que o método e atenção dispensados com a área de Ética de Cidadania são bastantes desiguais e estão de acordo com o perfil que cada IES visa conferir ao seu egresso ${ }^{6}$.

Complementando essa linha de estudo, um trabalho de 2005 apresentou um dilema moral a ser solucionado por alguns acadêmicos de Odontologia e, no final da pesquisa, 66\% dos alunos estavam classificados nos dois primeiros níveis de desenvolvimento moral, caracterizando a incapacidade de relativizar situações e impasses de cunho moral ou conseguir apenas resolvê-los baseado em interesses pessoais. O nível 1, encontrado em $16,6 \%$ da amostra, corresponde ao desenvolvimento moral percebido em crianças de 7 a 8 anos de idade. Já o nível 2, encontrado em metade dos formandos, caracteriza crianças por volta de 10 ou 11 anos de idade ${ }^{17}$. Esses resultados evidenciam que os profissionais recém-formados não estariam aptos a exercer uma Odontologia de forma a contribuir para a sociedade da maneira esperada.

Tendo em vista o progresso científico e aprimoramento da especialidade, a Associação Brasileira de Odontologia Legal (ABOL), composta por docentes, peritos e especialistas, elaborou, em março de 2014, um documento contendo diretrizes de apoio ao ensino da Odontologia Legal no Brasil. O documento tem aprovação da Associação Brasileira de Ensino Odontológico (ABENO) e as diretrizes, que foram cuidadosamente elaboradas por estudiosos da área, apresentam-se como importante amparo para o ensino da disciplina nos cursos de graduação em Odontologia $^{15}$. Sugere-se a divisão do conteúdo em duas cadeiras de 60 horas cada, sendo a primeira chamada de Deontologia e Diceologia. Essa deveria ser ministrada junto ao início das diciplinas clínicas e apresentar conteúdos sobre o Código de Ética Odontológica e Processo Ético, Lei 5081/66, Código de Defesa do Consumidor, documentação odontológica, honorários profissionais, sigilo profissional, noções de direito, abertura e montagem do empreendimento referente aos aspectos ético e legais. Para a segunda, sugere-se o nome de Odontologia Legal, a ser ministrada nos últimos períodos da graduação englobando os conteúdos de evolução histórica da Odontologia Legal, perícias e peritos, identidade e identificação, traumatologia forense, antropologia forense, infortunística, genética forense, balística forense, marcas de mordidas.

Outro ponto de vista muito importante elucidado por um estudo mais recente de 2010, é de que toda essa formação em questão deve ser amparada pelo exemplo dos docentes. A conduta do professor com o paciente é observada pelo es- 
tudante e, muitas vezes, reproduzida. Focar apenas em procedimentos técnicos e visualizar o paciente como um objeto de ensino e não como sujeito do processo de formação, pode resultar na formação de um cirurgião-dentista que não se preocupa com as consequências das suas ações para o paciente como um todo ${ }^{18}$.

A formação ética negligenciada pode trazer consequências ruins a longo prazo, pois o acadêmico vai deixar de ser estudante para ser um prestador de serviços à sociedade e, se os valores morais não estiverem consolidados, há uma grande tendência de descumprimento das normas básicas e desrespeito ao paciente. Mesmo que algumas decisões não dependam somente da vontade dos professores, é necessária a mobilização e conscientização do corpo docente. É no ambiente acadêmico de atendimento que o futuro CD aprende e adquire os hábitos da vida profissional. A presença do paciente no ensino dos estudantes de graduação não viola os princípios éticos, desde que sejam tratados em prol de suas necessidades de saúde e não como um meio para satisfação da ciência, além de ter seus direitos respeitados ${ }^{19}$.

Um exemplo é a conclusão de Garbin et. al. em seu trabalho de 2002, onde expõem-se claramente a existência de muitos cirurgiõesdentistas que possuem comportamento negligente com seus pacientes e ignoram os cuidados e informações que lhes são de direito ${ }^{20}$. Guimarães et. al. também conclui, em sua recente pesquisa de 2014, que o professor universitário favorece os ensinamentos técnicos em detrimento dos pedagógicos, baseado no padrão biomédico de docência, e os alunos de graduação em Odontologia possuem dificuldades no que diz respeito à sensibilidade social e preocupação com os problemas da população em geral $^{11}$.

Dessa maneira, reitera-se o quão imprescindível é o aprofundamento dos conhecimentos de Odontologia Legal na estrutura curricular da graduação. O CD depara-se com diversos obstáculos e é extremamente exigido frente ao cenário atual com casos clínicos cada vez mais complexos, disparidades sociais e novas tec- nologias. Cabe às IES capacitar o futuro profissional para enfrentar esses dilemas e fornecer mecanismos para desenvolver seu potencial afetivo, ter conceitos éticos inerentes à sua personalidade, atuar com conhecimento e domínio dos preceitos legais e ainda ter um conhecimento mais completo do seu campo de atuação.

Mesmo diante de um mercado competitivo, os profissionais devem ter sua formação baseada na ética e no bem de sua comunidade. No entanto, isso só pode ser atingido se, durante sua formação acadêmica, esses forem valores constantemente debatidos. Ter o diploma oficialmente reconhecido em mãos ao final do curso de graduação é apenas uma parte do processo para exercer a profissão. Conhecer integralmente as próprias áreas de competência e, principalmente, estar qualificado moralmente para exercer de maneira digna a prestação de serviço à sociedade, são outras responsabilidades indispensáveis. Sendo assim, há a necessidade de aperfeiçoamento dos aspectos supracitados, a fim de aprimorar os recursos humanos formados e trazer benefícios e saúde à sociedade.

\section{CONCLUSÃO}

Os cursos de graduação em Odontologia do Estado do Rio Grande do Sul carecem de aprimoramento e padronização quanto ao ensino dos conteúdos de Odontologia Legal. Constatouse que apenas uma pequena parcela oferta a Odontologia Legal como disciplina na estrutura curricular. Os cursos que não ofertam a Odontologia Legal como disciplina, mas possuem disciplinas relacionadas ou conteúdos pertencentes à área sendo ministrados esparsos em outras disciplinas são a maioria.

\section{ABSTRACT \\ Forensic Dentistry in higher education of Rio Grande do Sul State}

The teaching of Forensic Dentistry as a discipline in undergraduate courses takes an unique importance, since there is an increasing need to 
enable the student to a rising working area and to offer a humanistic education, always guided by ethical and legal precepts. Thus, it was realized an exploratory study about the presence of Forensic Dentistry and its related content in undergraduate Dentistry courses in the state of Rio Grande do Sul, through the analysis of their Pedagogic Projects. Fourteen projects $(93 \%)$ were analysed in this research. From an in-depht perspective, 36\% of these courses offer the Forensic Dentistry discipline, while $64 \%$ did not offer it. From a larger perspective, $93 \%$ of the courses cover some aspects of the knowledge of Forensic Dentistry, while $7 \%$ do not treat the issue. Therefore, it is necessary to standardize the teaching of Forensic Dentistry in undergraduation.

Descriptors: Forensic Odontology. Ethics, Dental. Education, Dental.

\section{REFERÊNCIAS}

1. Oliveira FT, Sales Peres A, Sales Peres SHC, Yarid SD, Silva RHA. Ética odontológica: conhecimento de acadêmicos e cirurgiõesdentistas sobre os aspectos éticos da profissão. Rev Odontol UNESP 2008; 37(1):33-9.

2. Gaudenzi EN. Ética e atualidade: algumas reflexões com enfoque nos profissionais da saúde. R Ci Méd Biol 2004 Jan-Jun; 3(1):13944.

3. Musse JO, Boing AF, Martino FS, Silva RHA, Vaccarezza GF, Ramos DLP. O ensino da bioética nos cursos de graduação em odontologia do estado de São Paulo. Arq Ciênc Saúde 2007 jan-mar; 14:13-6.

4. Caicedo CB. Necesidad de la bioética en la educación superior. Acta Bioethica 2006; 12(1):35-40.

5. De Freitas $\mathrm{SF}_{2}$ Kovaleski DF, Boing AF, de Oliveira WF. Stages of moral development among Brazilian dental students. J Dent Educ. 2006 Mar; 70(3):296-306.

6. Paula LM, Bezerra ACB. A estrutura curricular dos cursos de Odontologia no Brasil. Rev. ABENO 2003; 3(1):7-14.

7. Gonçalves PE. O perfil de ensino das disci- plinas de bioética, ética profissional (ou deontologia) e odontologia legal das faculdades de odontologia brasileiras [tese]. Araçatuba (São Paulo): UNESP Universidade Estadual Paulista; 2009.

8. Taquete SR, Rego S, Schramm FR, Soares LL, Carvalho SV. Situações eticamente conflituosas vivenciadas por estudantes de medicina. Rev Assoc Med Bras 2005; 51(1):23-8.

9. Lei $\mathrm{n}^{\circ}$ 5081, de 24 de agosto de 1966. Regula o exercício da Odontologia. Brasil. Senado Federal; 1966.

10. Resolução CFO 63/2005 (2005). Consolidação das Normas para Procedimentos nos Conselhos de Odontologia. Brasil. Conselho Federal de Odontologia; 2005.

11. Guimarães FAF, Mello ALSF, Pires ROM. Formação profissional em Odontologia: revisão de literatura. Rev Saúde Públ Santa Cat 2014 set-dez; 7(3):75-87.

12. Resolução CNE/CES 3/2002, de 04 de Março de 2002. Institui Diretrizes Curriculares Nacionais do Curso de Graduação em Odontologia. Brasil. Ministério da Educação e Cultura. Conselho Nacional de Educação. Diário Oficial da União, 04 Mar 2002.

13. Lemos CLS, Fonseca SG. Saberes e práticas curriculares: um estudo de um curso superior na área da saúde. Interface 2009 jan-mar; 13(28):57-69.

14. Gomes D, Ramos FRS. A subjetividade do profissional da Odontologia pósreestruturação produtiva: ética e especialização. Trab Educ Saúde 2015 maiago; 13(2):451-72.

15. Associação Brasileira de Ensino Odontológico. Associação Brasileira de Ética e Odontologia Legal. Diretrizes de Apoio ao ensino da Odontologia Legal, 04 Mar 2014. Acesso em 03 Nov 2015. Disponível em: http://www.abeno.org.br/PDFs/ABOL.pdf

16. Backes DS, Koerich MS, Erdmann AL. Humanizando el cuidado a través de la valori- 
zación del ser humano: resignificación de los valores y principios por los profesionales de salud. Rev Latino Am Enf 2007 jan-fev; 15(1):34-41.

17. Freitas SFT, Kovaleski DF, Boing AF. Desenvolvimento moral em formandos de um curso de Odontologia: uma avaliação construtivista. Ciênc Saúde Coletiva 2005; 10(2):453-62.

18. Puplaksis NV, Silva MMP, Nobile R, Ramos DLP. A disciplina de Bioética na Faculdade de Odontologia da Universidade de São Paulo. Rev Latinoam Bioética 2010 jul-dez; 10(2):68-75.
19. Gonçalves ER, Verdi MIM. Os problemas éticos no atendimento a pacientes na clínica odontológica de ensino. Ciênc Saúde Coletiva 2007; 12(3):755-64.

20. Garbin CAS, Mariano RQ, Machado TP, Garbin AJI. Estudo bioético das relações humanas no tratamento odontológico. Rev Faculdade Odontol Lins 2002 jan-jun; 14(1):54-9.

Correspondência para:

Sílvia Ataide Pithan

e-mail: silpithan@yahoo.com.br

Alameda dos Ipês, 159/03

Nossa Senhora Medianeira

97015-300 Santa Maria, RS 